\title{
The Effects of Job Security, Features, Personal Values, and Recognition on Organizational Involvement
}

\author{
Yacoub Petro \\ MWH UK Limited, Dubai, UAE \\ Arun Bajracharya \\ The British University in Dubai (BUiD), Dubai, UAE
}

\begin{abstract}
As extrinsic rewards become very limited under organizational retrenchments, organizations should rely heavily on other types of rewards, such as intrinsic rewards, to improve the performance of those employees who have been overwhelmed with a perception of job insecurity. This paper examines the impact of such perception, along with many other positive influencers such as enhancement in job features, recognition, and the personal values of those employees on the organizational involvement. The data analyzed were based on a sample of 34 employee respondents from a project based engineering and service company (identified as ABC Company in this paper) operating in the Middle East. The adopted research approach is basically a quantitative approach. The correlation and regression analysis tools have been used to explore this relationship. The results of this study suggest a generally unnoticed and disregarded resource that has the prime effect on improving and enhancing the organizational involvement, which is the recognition those employees receive from the management. This research suggests that recognition, as the top influencer, has a strong impact on organizational involvement/psychological attachment for the employees. The other factors that have proved to have the second degree influence on organizational involvement are enhancement in job features, increase in the job security level, and personal values.
\end{abstract}

Keywords: organizational involvement, job features, job security, values, recognition

\section{Background}

Time has changed for organizations and their employees. Organizations especially located in the UAE have sensed and learned about the profound effects financial crisis leave amongst their employees especially after the 2008 financial crisis. Such effects can be represented by demoralization, anxiety and fear of the future that all result into lower productivity (Rousseau, 1989). Those effects can linger in the organization and its employees for a long period of time even after the crisis is over. Reason behind this perpetual effect is that employees would lose their trust in the organization after a laying-off period followed by a financial crisis, this trust sometimes is represented by employees' loyalty and psychological attachment to the organization, or what researchers call the organizational involvement.

Yacoub Petro, MSc, PMP, Projects Manager, Project Management Departement, MWH UK Limited. Arun Bajracharya, BEng, MEng, Ph.D., Fuculty of Business, The British University in Dubai (BUiD). Correspondence concerning this article should be addressed to Yacoub Petro or Arun Bajracharya, United Arab Emirate, Dubai. E-mail: yacoub.petro@mwhglobal.com; yacoub.f.petro@gmail.com; arun.bajracharya@buid.ac.ae. 
This research looks into the effects of those harsh actions organizations take during such difficult times on the organizational involvement within the frame work of project based companies-i.e., companies whose revenue is generated by winning and executing projects. It also looks at the positive actions those companies take to improve the employees organizational involvement especially after a laying-off period. Those positive actions are meant to recover employees' loyalty and sense of involvement which could have been lost or withered during such harsh period. Those actions are: (1) recognition received by employees; and (2) improving on their job features as a bid to restore their loyalty and attachment. This paper also investigates those personal values that employees hold, and whether they coincide with those of the organization, and examines whether they have any effect on maintaining their sense of involvement.

\section{Research Question}

The recent 2008 financial crisis that hit the market had showed its effects spread at all kinds of organizations (Ivashina \& Scharfstein, 2010), with the construction, companies and developers amongst the top of the list. Most of the projects which were carried out by those companies were put on hold or cancelled due to lack of funding that got washed away by the crisis. Hence, laborers and workers were laid-off due to the result of insufficient revenue stream generated by their employer.

ABC Company is a private company which has more than 300 employees in the Middle East. It operates in the engineering and service industry and its revenue is generated by carrying out projects, most of which went on hold or canceled during and after the 2008 financial crisis. ABC Company, as is the case with other similar companies, resolved its internal crisis post the market catastrophe by laying-off part of their employees who were deemed to be redundant at that time. The remaining employees' motivation level plummeted after such severe laying-off period, and executives were concerned about the lingering perception of job insecurity that infested among the survivors post the crisis. They were mainly worried about the psychological detachment of those employees from the company which could result in lower productivity, higher turnover rates, and demotivation.

ABC Company, therefore, took many actions to revive the spirit of work amongst the employees to rebuild trust and eliminate any perceived injustice if there were any. Those actions varied from recognizing and awarding employees and/or enhancing their job features by promotion or salary increases. They hoped that such actions could wither the perception of job insecurity that spawned after the crisis, and hence improve their sense of involvement towards the company. ABC Company actions were supported by the recent market pick up and the new stream of project awards.

This research attempts to get answer on the question of whether the perception of job security and those other actions taken by ABC Company—such as enhancing job features and recognition—affect the employee's organizational involvement.

\section{Literature Review}

Organizational involvement stands for the psychological attachment employees have towards their work place - an organization can harness such attachment to increase their employees' and the organization's performance (Romzek, 1985). An organization, with such internal employee loyalty, can run with a lesser need for supervision, and thus lessens its requirements for unnecessary overheads (Simon, 1976). It can also increase 
its staff's motivation levels (Romzek, 1985) and enhance their performance under stressing situations (G. H. Gaertner, K. N. Gaertner, \& Devine, 1983). Etzioni (1974) devised an intensity continuum for the employees' psychological attachment towards their workplace with the two ends of the continuum which are: (1) the alienated; and (2) the strongly attached employee. Romzek and Hendricks (1982) related the values those employees hold, and the values of their relatives and friends, to the degree of the employee's psychological attachment to the organization. If those values were not in alignment with those of the organization, then there would be a high possibility of an alienated attachment, and vice versa. This shows the importance of human resource management in selecting new employees with proper cultural, and hence value, fits with the organization to reduce turnover rates (Robbins \& Judge, 2001). The first hypothesis is therefore:

Hypothesis 1: The personal values those employees share with the organization is positively related to organizational involvement.

Ingraham and Barrilleaux (1983) studied the variables affecting the organizational involvement for employees, and concluded that the fewer tendencies the organization is having towards promoting its employees, the less the psychological attachment they should expect from them. As a result of surveying and analyzing the data for 484 public organizations, Romzek (1985) and Romzek and Hendricks (1982) found a strong positive correlation between the recognition those employees receive and their attachment to the organization, especially among senior staff. They also found moderately strong correlations with high significance level between the organizational involvement and the job security perception.

The job security perception, drawing from Greenhalgh and Rosenblatt (1984) model combined with Romzek's (1985) findings, could be impaired by the management when they display: (1) lack of recognition—weak correlation with high significance as per Romzek (1985); (2) lack of timely and fair promotion—Romzek (1985); (3) an intention to negatively affect employees' job features—Greenhalgh and Rosenblatt (1984); and (4) the reality that there is no enough projects to substantiate the retention of all employees. It is the lack of trust and the perception of injustice stemmed from those actions the company take during a crisis that creates the feeling of helplessness among employees (Mishra \& Spreitzer, 1998). This feeling, as claimed by those researchers, is further exacerbated when employees have too many personal commitments, which make them financially attached to their job.

Greenhalgh and Rosenblatt (1984, p. 438) defined job insecurity as the "powerlessness to maintain desired continuity in a threatened job situation". The perceived feeling of job insecurity weakens the attachment that the employee has built with his/her workplace over the years of his/her tenure with the company (Ashford, Lee, \& Bobko, 1989). Greenhalgh and Rosenblatt (1984) presented a model of job insecurity which revolves around the threats that can affect an employee's job features, and such threat may constitute the employee's opportunity to lose an expected promotion. This threat is exacerbated by the employees' non-ability to defy it deeming him/her powerless, as shown in the below formula:

Job insecurity $=\left[\left(\sum\right.\right.$ importance of job feature $\times$ likelihood of losing job feature $)+\left(\sum\right.$ importance of job loss $\times$ likelihood of Job loss)] $\times$ perceived powerlessness to resist threat

The employee's sense of loyalty towards his/her works place, and the intensity of his/her psychological attachment to the organization, strengthens the psychological contract that he/she has with the organization. The psychological contract in this case is the invisible contract constituting the shared beliefs about the mutual 
responsibilities between the employee and his/her organization apart from any written contract (Rousseau, 1989). Violations to the psychological contract can be initiated by the organization as a result of downsizing, laying-offs during difficult times, reducing pays and job features (Morrison \& Robinson, 1997)—all this breeds job insecurity perception among the staff and could affect their organizational involvement. Robinson, Kraatz, and Rousseau (1994) and Robinson and Rousseau (1994) claimed that all such violations ruins employees' trust towards the organization, and mars their psychological attachment and loyalty towards the organization.

On the other hand, it has been argued that a period of lay-off could in some cases improve the employees' attachment to the organization, and as the matter of fact, could increase their performance in some other cases (Brockner et al., 1986). Those cases are applicable to the employees whose tenure or job features were not affected by the crisis. Their positive feeling of job security in this instance emanates from the sense of obligation they feel towards the organization after having the decision to spare their jobs. Such feeling creates a sense of guilt and a positive feeling of equity which drive the employee to work harder and express a positive attachment to the organization (McKenna, 2006).

Drawing from the literature about job security, enhancing job features, and the effects of job recognition on employees moral, therefore, there are three hypotheses:

Hypothesis 2: The amount of recognition the employees receive from the organization is positively related to organizational involvement.

Hypothesis 3: The nature and magnitude of employees' job features they have within the organization is positively related to organizational involvement.

Hypothesis 4: The amount of job security the employees perceive is positively related to organizational involvement.

\section{Conceptual Framework}

As is outlined in the literature review, the conceptual framework looks at the organizational involvement as the dependent variable which is represented by the employee's psychological attachment towards the organization. The relationship of the dependent variable is tested against the following independent variables: (1) perception of job security; (2) regular enhancement in job features such as promotion; (3) recognition provided by management; and (4) the values those employees share with the organization. Figure 1 represents those relationships.

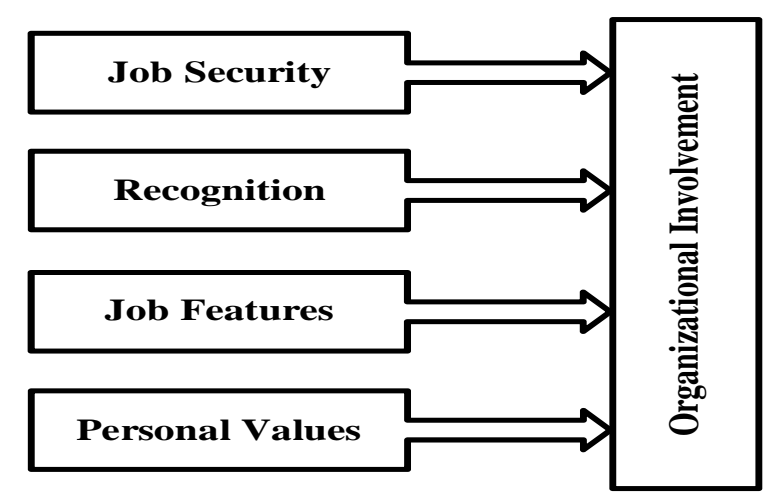

Figure 1. Conceptual framework. 


\section{Methodology}

The quantitative approach has been used in this research in order to test the relationship between the set of variables indicated in the conceptual framework. The analysis of the data, which were collected for this research, followed the examination of 34 responses received from an equal-probability based on random sampling selected from the total population of 300 employees based on ABC Company. Those 34 structured responses adhered to a self-administered questionnaire survey distributed for full time employees. The questions pertaining to identified variables were asked in the questionnaire in the format of a 5-point Likert scale with “ 1 ” denoting high agreement.

The organizational involvement variable measures the degree of loyalty and psychological attachment of those employees towards their workplace. It varies from alienated to fully attached employees, and is considered as a dependent variable in this research as it is affected by various other variables as suggested in the literature.

The job security variable measures the amount that the employees perceive they are secured in their current tenure. A low level of job security, which denotes a perception of job insecurity in this case, reflects the employees' dissatisfaction with their security level and that could result in their feeling of anxiety, demoralization and demotivation.

The recognition variable reflects the amount of the recognition and respect those employees receive from their superiors and the organization. The job features variable measure the extent of the potential that the management has towards promoting their employees and providing them with proper working conditions. A high measure of job features reflects the employees' satisfaction with the frequency of promotion and remuneration reviews, as well as a satisfaction towards their working conditions.

The personal values variable measures the degree of acceptance of those values of the organization presented by the employees, those values the employees hold are a mere reflection of their own paradigm and they are not easily changed. A low measure of personal value replicate the degree of alienation and divergence of those values that the employees hold from those presented by the company's operations.

Each variable has been administered through four survey item questions. The reliability of the respective set of question items has been tested post the analysis to adjust the reliability measure for each of those discussed variables. Table 1 shows a moderate to strong internal reliability based on the cut-off Cornbach's alpha value of 0.65 .

Table 1

Cronbach's Alpha, Descriptive Statistics, and One Sample t-test of the Sample Means

\begin{tabular}{lllllll}
\hline Scale & Cornbach's alpha & No. of items & Mean $(X)$ & STD & $t$-test & Sig $^{*}$ \\
\hline Organization involvement & 0.79 & 2 & 1.82 & 0.26 & 0.030 & 0.976 \\
Job security & 0.70 & 4 & 3.00 & 0.91 & -0.124 & 0.902 \\
Recognition & 0.75 & 4 & 2.19 & 0.46 & -0.007 & 0.995 \\
Job features & 0.71 & 2 & 2.86 & 1.28 & -0.041 & 0.967 \\
Personal values & 0.65 & 4 & 2.24 & 0.70 & -0.051 & 0.960 \\
\hline
\end{tabular}

Notes. ${ }^{*}$ Two tailed. Source: SPSS software data analysis. 


\section{Analysis, Findings, and Discussions}

The relationship between organizational involvement, job security, recognition, job features, and personal values was investigated using Spearman correlation coefficient, as shown in Table 2. It has been found that there is a moderate positive correlation between job security, recognition on one side, and the organizational involvement on the other side with a strong significance level, $p<0.01$. The correlation among job features, personal values, and the organizational involvement has found to be positively weak with significance level indicated by $p<0.05$. These findings support Hypotheses 1, 2, 3, and 4.

Table 2

Correlation Coefficient Between Variables

\begin{tabular}{llllll}
\hline & Org. Inv. & Job security & Recognition & Job features & Per. values \\
\hline Organizational involvement & 1 & & & & \\
Job security & $0.436^{* *}$ & 1 & & & \\
Recognition & $0.493^{* *}$ & $0.563^{* *}$ & 1 & 1 & \\
Job features & $0.318^{*}$ & $0.524^{* *}$ & $0.532^{* *}$ & 0.133 & 1 \\
Personal values & $0.393^{*}$ & $0.324^{*}$ & 0.279 & \\
\hline
\end{tabular}

Notes. $^{* *}$ Correlation is significant at the 0.01 level; ${ }^{*}$ Correlation is significant at the 0.05 level. Source: SPSS software data analysis.

Table 2 suggests moderate correlation with strong significance level among most of the variables, with the exception of personal values versus recognition. Therefore, the chance of collinearity could be of a high concern when performing a linear regression analysis amongst all the variables. Hence, the linear regression has been performed to test the sensitivity of the organizational involvement as a dependent variable towards recognition and personal values only both acting as independent variables. Tables 3, 4, and 5 provide the outcome of this analysis.

Table 3

Values of Adjusted R Square and Durbin Watson

\begin{tabular}{llll}
\hline$R$ square & Adjusted $R$ square & Std. error of the estimate & Durbin-Watson \\
\hline 0.315 & 0.267 & 0.38337 & 2.062 \\
\hline
\end{tabular}

Note. Source: SPSS software data analysis.

Table 4

ANOVA

\begin{tabular}{llllll}
\hline Model & Sum of squares & $d f$ & Mean square & $F$ & Sig. \\
\hline 1 & 1.956 & 2 & 0.978 & 6.656 & 0.004 \\
& 4.262 & 29 & 0.147 & & \\
\hline
\end{tabular}

Note. Source: SPSS software data analysis.

Table 5

Beta Coefficient and Collinearity Tests

\begin{tabular}{|c|c|c|c|c|c|c|c|}
\hline \multirow{2}{*}{ Model } & \multicolumn{2}{|c|}{ Unstandardized coefficients } & \multicolumn{3}{|c|}{ Standardized coefficients } & \multicolumn{2}{|c|}{ Collinearity statistics } \\
\hline & $\mathrm{B}$ & Std. error & Beta & $T$ & Sig. & Tolerance & VIF \\
\hline (Constant) & 0.728 & 0.354 & & 2.057 & 0.049 & & \\
\hline Recognition & 0.449 & 0.138 & 0.519 & 3.257 & 0.003 & 0.929 & 1.076 \\
\hline Personal values & 0.087 & 0.121 & 0.114 & 0.718 & 0.479 & 0.929 & 1.076 \\
\hline
\end{tabular}

Notes. a. Dependent variable: Organizational involvement. Source: SPSS software data analysis. 
Table 5 reveals that collinearity is not an issue. Likewise, ANOVA as shown in Table 4 reveals that the overall model is significant.

Table 3 shows that $26.7 \%$ of the variance in the organizational involvement could be explained by the variability of the independent variables. However, by inspecting the Beta values for both independent variables-recognition and personal values (see Table 5), it is noticed that the Beta value for recognition is much higher than that for the personal values -0.519 and 0.114 respectively, with high significance value for recognition, $p<0.01$. This implies that the recognition variable makes the strongest unique contribution to explaining the dependent variable organizational involvement.

The outcome of the regression analysis stresses on the correctness and acceptance of Hypothesis 2, which states that organizational involvement is positively related to the amount of recognition that the employees receive from the organization. Thus, it can be argued that organizational involvement is more sensitive to recognition than personal values.

Since the other variables of job features and job security have moderate to strong correlation with high significance with the recognition variable, as shown in the correlation coefficients in Table 2 with $r=0.532$ and 0.563 respectively - the reason they were omitted from regression analysis from the first place, and it could be inferred then that the organizational involvement is also sensitive to those variables by the same case of recognition, but with much lesser degree than recognition.

\section{Conclusions and Recommendations}

The findings presented in this research provide some valuable information about organizational involvement, and how companies can work towards improving its level amongst their employees, and thus increasing the employees' loyalty and psychological attachment towards their workplace. Beleaguered organizations are forced sometimes to sack part of their employees especially during difficult time when revenue streams generated cannot support the retention of all their employees. Hence, part of their staff should be released to relieve the organization from those extra financial burdens allowing the organization to recuperate from the loss in revenue.

Survivors, deluged with perception of job insecurity after such actions, usually act negatively; they nurture feeling of anxiety and fear which may breed low productivity and carelessness towards their work. All such feelings emanate from their loss of faith with their employer after violating their psychological contract, and/or after the company have rendered their colleagues redundant. Those organizations desire to regain their employees' trust and loyalty back, and win their involvement with the organization.

The findings of this research suggested that loss of job security will invariably be associated with loss of the employees' psychological attachment to the organization and their loyalty as well, i.e., organizational involvement. In order to increase the sense of job security, as stated by Mishra and Spreitzer (1998), those organizations need to increase the level of trust among the employees, they should try to annihilate any perceived feeling of injustice created as well, and this can be achieved by talking to those employees and persuading them that such actions were beyond their control. Mishra and Spreitzer (1998) suggested redesigning the jobs of those survivors, and Hammuda and Dulaimi (1997, p. 295) suggested not to waste any promotion opportunity for them. Enhancing those survivors' job features will also enhance the sense of 
organizational involvement which was impaired, and, as established in the analysis, it will also help in reducing the job insecurity perception.

One of the most sensitive variables, as found in this research, towards improving organization involvement is recognition. Organizations concerned with fostering and maintaining their employees' organization involvement especially in such period of forced cutbacks—-which was the case with ABC Company-face restrictions in the disposal of extrinsic rewards. Having the ability to dispose these rewards negates their inability to retain all their employees from the first place. Under such situations, it would be wise for these organizations to demonstrate their recognition to their employees. Recognition comes free of cost and is considered as an important part of intrinsic rewards. Recognizing employees and respecting them for their work is a simple and a humble way to regain their trust in the organization and proved very effective in improving their sense of organizational involvement.

\section{References}

Ashford, S. J., Lee. C., \& Bobko, P. (1989). Content, causes, and consequences of job insecurity: A theory-based measure and substantive test. The Academy of Management Journal, 32(4), 803-829.

Brockner, J., Greenberg, J., Brockner, A., Bortz, J., Davy, J., \& Carter, C. (1986). Layoffs, equity theory, and work performance: Further evidence of the impact of survivor guilt. The Academy of Management Journal, 29(2), 373-384.

Etzioni, A. (1974). A comparative analysis of complex organizations. New York: Macmillan.

Gaertner, G. H., Gaertner, K. N., \& Devine, I. (1983). Federal agencies in a context of transition: A contrast between demographic and organizational theories. Public Administration Review, 43, 421-432.

Greenhalgh, L., \& Rosenblatt, Z. (1984). Job insecurity: Toward conceptual clarity. The Academy of Management Review, 9(3), 438-448.

Hammuda, I., \& Dulaimi, M. F. (1997). The theory and application of empowerment in construction: A comparative study of the different approaches to empowerment in construction, service and manufacturing industries. International Journal of Project Management, 15(2), 289-296.

Ingraham, P. W., \& Barrilleaux, C. (1983). Motivating government managers for retrenchment: Some possible lessons from the senior executive service. Public Administration Review, 43, 393-402.

Ivashina, V., \& Scharfstein, D. (2010). Bank lending during the financial crisis of 2008. Journal of Financial Economics, 97(3), 319-338.

McKenna, E. (2006). Business psychology and organizational behavior. Hove: Psychology Press.

Mishra, A. K., \& Spreitzer, G. M. (1998). Explaining how survivors respond to downsizing: The role of trust, empowerment, justice, and work redesign. The Academy of Management Review, 23(3), 567-588.

Morrison, E. W., \& Robinson, S. L. (1997). A model of how psychological contract violation develops. The Academy of Management Review, 22(1), 226-256.

Robbins, S., \& Judge, T. A. (2001). Organizational behavior. New Jersey: Pearson Education Inc..

Robinson, S. L., \& Rousseau, D. M. (1994). Violating the psychological contract: Not the exception but the norm. Journal of Organizational Behavior, 15, 245-259.

Robinson, S. L., Kraatz, M. S., \& Rousseau, D. M. (1994). Changing obligations and the psychological contract: A longitudinal study. Academy of Management Review, 37, 137-152.

Romzek, B. S. (1985). The effects of public service recognition, job security and staff reductions on organizational involvement. Public Administration Review, 45(2), 282-291.

Romzek, B. S., \& Hendricks, J. S. (1982). Organizational involvement and representative bureaucracy: Can we have it both ways? American Political Science Review, 76, 75-82.

Rousseau, D. M. (1989). Psychological and implied contracts in organizations. Employee Responsibilities and Rights Journal, 2, 121-139.

Simon, H. (1976). Administrative behavior. New York: Macmillan.

Stutely, M. (2003). Numbers guide: The essentials for business numeracy. London: Bloomberg press. 